\title{
DIFFICULTIES IN IDENTIFYING AND TRANSLATING LINGUISTIC METAPHORS: A SURVEY AND EXPERIMENT AMONG TRANSLATION STUDENTS
}

\author{
Charlène Meyers \\ Université de Mons, Belgium
}

\begin{abstract}
A survey of twelve translation students in 2017 revealed that they tend to find translating figurative and metaphorical language difficult. In addition, an experiment also conducted in 2017 showed similar results. During the first phase of this experiment, two trained researchers coded metaphorical items in a text from the New Scientist following the Metaphor Identification Procedure Vrije Universiteit Amsterdam (MIPVU). Based on Cohen's kappa, the researchers reached an initial coding agreement of 0.692 (strong agreement) and a final agreement score of 0.958 (almost perfect agreement) after discussion. The second phase of the experiment involved the coding of the metaphorical items previously identified by the researchers in the same text by 47 students who received a two-hour introduction to conceptual metaphor theory and a simplified method to code metaphorical items. However, the results of the students' coding showed that they had failed to identify metaphors in $49.96 \%$ of cases. Nevertheless, a chi-squared test $\left(p<2.2^{-16}\right)$ revealed that the students' coding was not due to chance alone and therefore not arbitrary.
\end{abstract}

Keywords: metaphor-related words, metaphor identification procedure, translation studies

\section{Article history:}

Received: 27 November 2019;

Reviewed: 2 December 2019;

Revised: 5 December 2019;

Accepted: 20 December 2019;

Published: 30 December 2019

Copyright (C) 2019 Charlène Meyers

(7) (5) This open access article is published and distributed under a CC BY-NC 4.0 International License which permits non-commercial use, distribution, and reproduction in any medium, provided the original author and source are credited. Permissions beyond the scope of this license may be available at charlene.meyers@umons.ac.be. If you want to use the work commercially, you must first get the authors' permission.

Citation: Meyers, C. (2019). Difficulties In Identifying and Translating Linguistic Metaphors: A Survey and Experiment among Translation Students. English Studies at NBU, 5(2), 308-322.

https://doi.org/10.33919/esnbu.19.2.7

Charlène Meyers is a translator and a PhD student at the University of Mons (FTI-EII) in Belgium where she received a Master's degree in translation in 2012 and a Specialized Master's degree in applied linguistics in 2013. She is currently a research and teaching assistant in the Specialized Translation and Terminology Unit directed by Professor Christine Michaux. Meyers' ongoing thesis is a contrastive study (French/English) of conceptual metaphors in astrophysics. Her research interests include cognitive linguistics, specialized translation and terminology.

E-mail:charlene.meyers@umons.ac.be

https://orcid.org/0000-0002-2548-3227 


\section{The use of metaphors in language for specific purposes}

Before the cognitive turn of linguistics in the seventies, metaphors had long been solely considered as ornamental figures with the aim of adding a stylistic effect to a text. However, the study of metaphors as conceptual objects, initially proposed through the conceptual metaphor theory by Lakoff \& Johnson in 1980, proved that metaphors were more than mere ornamental figures and could be understood as ways to conceptualize the world or any kind of action or phenomenon: "Metaphor is not simply an ornamental aspect of language, but a fundamental scheme by which people conceptualize the world and their own activities" (Gibbs, 2008, p. 3).

According to Lakoff \& Johnson, metaphor is a matter of thought, because it shapes our way of thinking and acting which they call our conceptual system: "Our ordinary conceptual system, in terms of which we both think and act, is fundamentally metaphorical in nature." (1980, p. 454)

Since communication relies on the same conceptual system used to think and act, language is a good indicator of the metaphorical nature of that system: "[...] language is an important source of evidence for what that system is like" (1980, p. 454). Therefore, even though the basis of conceptual metaphors is cognitive, there is evidence of their presence in language.

A conceptual metaphor enables the understanding of an idea or a concept in terms of another. It can be defined as a cognitive mapping from a source domain to a target domain: "In short, the locus of metaphor is [...] in the way we conceptualize one mental domain in terms of another" (Lakoff, 1993, p. 203).

For instance, ARGUMENT IS WAR ${ }^{1}$ is a good example given by Lakoff \& Johnson (1980) to demonstrate what a conceptual metaphor is. In ARGUMENT IS WAR, there is a mapping from the source domain of WAR onto the target domain of ARGUMENT. The structure of argument is experienced, thought of, visualized, etc. in terms of war; the human mind tends to conceive argumentation as a war, which gives rise to various linguistic realizations expressing this conceptual metaphor, such as "he attacked every

\footnotetext{
${ }^{1}$ Conceptual metaphors are conventionally written in small capital letters.
} 
weak point in my argument" (1980, p.454), “your claims are indefensible” (1980, p.454), "I've never won an argument with him" (1980, p.454), etc.:

The essence of metaphor is understanding and experiencing one kind of thing in terms of another. It is not that arguments are a subspecies of war. Arguments and wars are different kinds of things - verbal discourse and armed conflict and the actions performed are different kinds of actions. But ARGUMENT is partially structured, understood, performed, and talked about in terms of WAR. The concept is metaphorically structured, the activity is metaphorically structured, and, consequently, the language is metaphorically structured. (Lakoff \& Johnson, 1980, p. 455)

In other words, conceptual metaphors are mappings (ARGUMENT IS WAR) that occur at the cognitive level and that are found in language through linguistic realizations (“your claims are indefensible" (1980, p. 454)):

It is now widely agreed that metaphor is a cognitive phenomenon, and a mass of evidence has been accumulated to support the proposition that many linguistic metaphors, especially those that are most conventionalized and embedded in the language are realizations of mental mappings. (Deignan, 2008, p. 287)

The conceptual metaphor theory also stresses that metaphors are "pervasive in everyday life" (Lakoff \& Johnson, 1980, p. 454), as human thought is highly metaphorical in essence. Since conceptual metaphors structure everyday life and since their linguistic realizations are present in language, translators and student translators also have to deal with conceptual metaphors and more specifically with their linguistic realizations in the various texts they translate.

This study aims to show how student translators cope with identifying and translating linguistic realizations of conceptual metaphors in vulgarized scientific texts: twelve students were surveyed about their ability to identify and translate metaphorical language in two texts. In addition, the ability of 47 students to identify the linguistic realizations of conceptual metaphors in one text was tested in an experiment by comparing their coding with the coding made by two researchers. 


\section{Students' difficulties in translating metaphorical language: a survey}

Translation students tend to have difficulties dealing with metaphors and figurative language in their translations. A short survey of twelve Master's students in translation, conducted in 2017, indeed revealed that students are to some extent aware of the metaphoricity of a text but find it hard to translate metaphors.

Students were first asked to translate in French two texts about black holes from Scientific American ("The Benevolence of Black Holes" and "An Echo of Black Holes") and then to answer a questionnaire aimed at testing their awareness of metaphors in the two texts. The first part of the survey consisted of different questions, including some about figurative language. The word "metaphor" was deliberately left out of the survey in order not to influence the students in their answers. That is why the words "figurative language" were preferred.

One of the questions was "Considérez-vous que le langage du texte que vous avez traduit était 'imagé'?" [Did you perceive the language of the text as being figurative?] ${ }^{2}$ All students answered "yes" to that question, which means that they were somewhat aware that the language in the source text was figurative.

In the next question, students were asked to explain why they perceived the language in the text as figurative. Here is a sample of their answers:

- "Des métaphores étaient utilisées comme, par exemple, black holes keep the galaxy's stellar population at a perfect simmer." (ID: 2 ] $^{3}$ ["Some metaphors were used, as in the following example: 'black holes keep the galaxy's stellar population at a perfect simmer'."]

- “Une phrase qui m’avait marquée tant elle était imagée était celle qui concernait l'horizon et plus particulièrement ce qu'il se passe lorsqu'une particule de la paire de photons passe cet horizon." (ID: 5) ["There was one sentence that struck me because it was so figurative. It was about the horizon and more specifically about what happens when a particle from the pair of photons passes through this horizon."]

\footnotetext{
${ }^{2}$ Text between brackets is the author's translation.

3 The online survey tool that was used, called Lime Survey, automatically anonymized students' names and replaced them with an identification number.
} 
- ' 'L'auteur comparait souvent les trous noirs à d'autres choses, probablement afin de le rendre plus abordable." (ID: 6) ["The author often compared black holes with other things, probably to make the text more accessible."]

- "Les trous noirs étaient comparés à des monstres. Le texte faisait référence à des démons libérés durant la création des trous noirs. Il mentionnait également des maisons de retraite et des cimetières pour les étoiles. Une galaxie recevait 'a kick in the pants'." (ID: 9) [“Black holes were compared with monsters. In the text, there were references to demons, which were unleashed during the creation of black holes. The author also wrote about nursing homes and graveyards for stars. A galaxy received a 'kick in the pants'."]

In his/her answer, student \#2 explains that he/she found the language was figurative because of the presence of metaphors. It should be stressed that student \#2 deliberately used the word "metaphor" on his/her own. While student \#5 expressed his/her puzzlement about the figurative aspect of one sentence, students \#6 and \#9 argued that the text was figurative because black holes were compared with other things, such as monsters. Hence, the students' answers clearly demonstrate they perceived the text as figurative and/or metaphorical.

The second part of the survey involved reading tasks. Students were asked to read the following excerpt (that was taken from the source text used for the translation task) and to decide whether it contained figurative language: "Somewhere in between the zones of forming and exploding young stars and the nursing homes and graveyards of ancient ones is a place that is "just so", and our solar system resides in such an environment." In total, $83.33 \%$ of the students said that the excerpt was figurative. Then, students were asked to explain why they found it to be figurative. Here are some of their answers:

- "On utilise des termes comme maison de retraite ou cimetière pour parler d'astrophysique." (ID: 2) [“Terms such as nursing home and graveyard are used to talk about astrophysics."]

- 'Je ne comprends pas le rapport entre les 'nursing homes', les 'graveyards' et les étoiles..." (ID: 6) [“I do not understand the relationship between 'nursing homes', 'graveyards' and the stars..."]

- "Personnification des étoiles." (ID: 8) [“Personification of stars.”] 
- "Car les étoiles sont comparées à des êtres humains." (ID: 9] [“Because stars are compared with human beings."]

Again, the answers show that students perceived the language as being figurative. Student \#2's answer pointed to the mapping between the source domain of human facilities with the use of the words "nursing homes" and "graveyards" and the target domain of astrophysics. Students \#8 and \#9 identified the metaphorical personification of stars. In addition, student \# 6 admitted he/she did not understand why stars might live in nursing homes and end up in graveyards. It seemed difficult for him/her to understand the metaphorical mapping in the excerpt: he/she identified the source domain by naming the human facilities such as "nursing homes" and "graveyards" as well as the target domain represented by the "stars", but failed to grasp the mapping (or "the relationship" in his/her own words) between the domains.

Subsequently, students were asked to decide whether the same excerpt was difficult to translate. All of them answered "yes" to that question. Here is how a few of them justified their answers:

- "Structure syntaxique, difficulté de rendre les images en FR." (ID: 4) ["Because of the syntax of the sentence and because it is difficult to render the images in French."]

- "Beaucoup de 'and', et le passage est très imagé." (ID: 6) [“There were a lot of instances of 'and', and the excerpt was also very figurative."]

- "Il faut trouver une image semblable en français et la rendre harmonieuse." (ID: 8) ["It is necessary to find a similar image in French and to make it fit in the target text."]

- "D’abord, car la phrase est assez longue, il y a de nombreux éléments à placer et ensuite, car une 'maison de retraite pour étoiles' ne passe pas très bien en français." (ID: 9) ["First, the sentence is quite long. There are a lot of elements to position in this sentence and because 'a nursing home for stars' is not quite suitable in French."]

Overall, many arguments in the students' answers stress the difficulty of translating the figurative aspects of the text. 


\section{A method for identifying linguistic metaphors}

As mentioned above, conceptual metaphors are the result of a cognitive mapping, while their realizations in language are linguistic. Researchers can identify conceptual metaphors based on their linguistic realizations and name them according to their intuition: conceptual metaphors are labelled according to the semantic interpretation that the reader or researcher gives to the linguistic realizations that lead to these conceptual metaphors. There is no fixed method to determine how to systematically identify and therefore label conceptual metaphors.

In contrast, a successful method has been created to identify the linguistic realizations underlying the conceptual metaphors. The first version of this method was developed by Steen et al. (2007) and called the Metaphor Identification Procedure (MIP). It was revised afterwards resulting in a second version (Steen et al., 2010): the Metaphor Identification Procedure Vrije Universiteit Amsterdam (MIPVU). Both versions of the method enable the identification of metaphor-related words (MRWs). MRWs are the linguistic realizations of conceptual metaphors ${ }^{4}$.

Both the MIP and the MIPVU are conceived to be followed on a step-by-step basis to facilitate the decision-making process. Several types of metaphor-related words can be identified: indirect metaphorically used words (indirect MRWs), direct metaphorically used words (direct MRWs), ellipses and lexico-grammatical substitutions used metaphorically (implicit MRWs), and finally words that signal a potential cross-domain mapping, i.e. metaphor flags (MFlags). This study only focuses on indirect MRWs and direct MRWs.

An indirect MRW is a word with a contextual meaning that differs from its more basic meaning but can be understood in comparison to this basic meaning. Finding indirect metaphor-related words is defined as follows in the MIPVU:

Indirect use of lexical units which may be explained by a cross-domain mapping is basically identified by means of MIP, with some adjustments. This means that the following guidelines should be adopted:

\footnotetext{
${ }^{4}$ Since both the mapping and the linguistic realizations are sometimes simply called "metaphors" and because of the confusion the various terminologies may entail, from now on I will refer to cognitive mappings as conceptual metaphors in the words of Lakoff \& Johnson (1980) and to their linguistic realizations as the metaphor-related words, as they are defined by Steen et al. (2010).
} 
1. Identify the contextual meaning of the lexical unit.

2. Check if there is a more basic meaning of the lexical unit. If there is, establish its identity.

3. Determine whether the more basic meaning of the lexical unit is sufficiently distinct from the contextual meaning.

4. Examine whether the contextual meaning of the lexical unit can be related to the more basic meaning by some form of similarity.

If the results of instructions 2,3 , and 4 are positive, then a lexical unit should be marked as a metaphor-related word ('MRW'), which may be made more precise by adding the information that it is 'indirect' (as opposed to 'direct' or 'implicit', see below). (Steen et al., 2010, pp. 32-33)

Direct MRWs are words for which the metaphorical mapping is made clear, most often by the presence of both the source domain and the target domain in context. Here is the procedure to find a direct MRW described in the MIPVU:

1. Find local referent and topic shifts. - Good clues are provided by lexis which is "incongruous" (Cameron, 2003; Charteris-Black, 2004) with the rest of the text.

2. Test whether the incongruous lexical units are to be integrated within the overall referential and/or topical framework by means of some form of comparison. - Good clues are provided by lexis which flags the need for some form of similarity or projection (Goatly, 1997).

3. Test whether the comparison is nonliteral or cross-domain. - Cameron (2003, p. 74) suggests that we should include any comparison that is not obviously nonmetaphorical, such as the campsite was like a holiday village. Consequently, whenever two concepts are compared and they can be constructed, in context, as somehow belonging to two distinct and contrasted domains, the comparison should be seen as expressing a cross-domain mapping. Cameron refers to these as two incongruous domains.

4. Test whether the comparison can be seen as some form of indirect discourse about the local or main referent or topic of the text. - A provisional sketch of a mapping between the incongruous material functioning as source domain on the 
one hand and elements from the co-text functioning as target domain on the other should be possible.

If the findings of tests 2,3 , and 4 are positive, then a word should be marked for direct metaphor ('MRW, direct'). (Steen et al., 2010, pp. 38-39)

The MIPVU was applied in the experiment described below by two researchers to identify MRWs and by students (in a simplified version) to corollate their identification of direct and indirect MRWs with the researchers' and therefore evaluate their abilities to identify linguistic realizations of conceptual metaphors.

\section{Students' difficulties in identifying metaphorical items: an experiment}

An experiment also carried out in 2017 has shown that 47 Master's students in translation failed to recognize metaphorical items in a source text about astrophysics in half of the cases even after having taken part in a two-hour seminar about metaphors and coding. The experiment was divided in two phases: in the first phase, two researchers identified MRWs in a text about astrophysics from the New Scientist, then selected 21 MRWs. In the second phase, 47 Master's students in translation became acquainted with the same text in a sight translation class. The week following the sight translation class, students received a two-hour introduction to conceptual metaphor theory and a simplified method for coding metaphorical items. They were then asked to code the 21 selected items in context to decide whether those items were metaphorical.

\section{Methodology of the coding experiment}

In the first phase of the experiment, a source text about astrophysics in English was coded for metaphor-related words by two researchers specializing in metaphor theory. The MIPVU (Steen et al., 2010) was applied to identify the different lexical units of a text and to code those lexical units for direct MRWs, indirect MRWs and MFlags by the two researchers.

Inter-rater agreement was calculated to check for coding reliability between the two researchers thanks to Cohen's kappa. Inter-rater agreement helps researchers remove bias that can come from their personal interpretation of the data:

When one has to decide whether a word in a corpus is used metaphorically or not, or to perform any other kind of semantic association, it is useful to collect 
opinions of different annotators and check if they tend to agree or disagree. A well-known measure of inter-rater agreement is Cohen's $k$ ('kappa'). It is based on the observed proportions of inter-rater agreement and disagreement compared to the expected proportions. [...] Similar to correlation coefficients, the scores range from [...] -1 (complete disagreement) to 1 (full agreement). (Levshina, 2015, p. 201)

The inter-rater agreement was calculated ${ }^{5}$ in three steps: during the first step, the score was calculated on the coding of direct MRWs and indirect MRWs only, as the MIPVU recommends overlooking the coding of MFlags in the inter-rater agreement calculation. The results are shown in Table 1:

Table 1

Inter-rater agreement on MRWs

\begin{tabular}{lcccccc} 
& $\begin{array}{l}\text { Percent } \\
\text { Agreement }\end{array}$ & $\begin{array}{l}\text { Cohen's } \\
\text { Kappa }\end{array}$ & $\begin{array}{c}\text { Number of } \\
\text { agreements }\end{array}$ & $\begin{array}{c}\text { Number of } \\
\text { disagreements }\end{array}$ & $\begin{array}{c}\text { Number } \\
\text { of cases }\end{array}$ & $\begin{array}{c}\text { Number of } \\
\text { decisions }\end{array}$ \\
\hline $\begin{array}{l}\text { Indirect } \\
\text { MRWs }\end{array}$ & $93.3 \%$ & 0.697 & 457 & 33 & 490 & 980 \\
\hline $\begin{array}{l}\text { Direct } \\
\text { MRWs }\end{array}$ & $99.6 \%$ & 0.665 & 488 & 2 & 490 & 980 \\
\hline
\end{tabular}

The Cohen's Kappa reached for both indirect and direct MRWs is respectively of 0.697 and 0.665 . Those results can be interpreted as substantial agreement between the two raters: "Cohen suggested the Kappa result be interpreted as follows: values $\leq 0$ as indicating no agreement and $0.001-0.20$ as none to slight, $0.21-0.40$ as fair, $0.41-0.60$ as moderate, 0.61-0.80 as substantial, and 0.81-1.00 as almost perfect agreement" (McHugh, 2012, p. 279).

During the second step, the inter-rater agreement was calculated on metaphoricity only (regardless of the items being direct or indirect MRWs), as advised by the MIPVU. The inter-rater agreement score reached by the researchers showed a Cohen's kappa of 0.692 , which is also representative of "substantial agreement" (McHugh, 2012, p. 279). The results are depicted in Table 2:

Table 2

Inter-rater agreement on metaphoricity

\begin{tabular}{lcccccc} 
& $\begin{array}{l}\text { Percent } \\
\text { Agreement }\end{array}$ & $\begin{array}{l}\text { Cohen's } \\
\text { Kappa }\end{array}$ & $\begin{array}{l}\text { Number of } \\
\text { Agreements }\end{array}$ & $\begin{array}{l}\text { Number of } \\
\text { Disagreements }\end{array}$ & $\begin{array}{l}\text { Number } \\
\text { of cases }\end{array}$ & $\begin{array}{l}\text { Number of } \\
\text { decisions }\end{array}$ \\
\hline $\begin{array}{l}\text { Inter-rater } \\
\text { agreement } \\
\text { before } \\
\text { discussion }\end{array}$ & $92.9 \%$ & 0.692 & 455 & 35 & 490 & 980 \\
\hline
\end{tabular}

\footnotetext{
${ }^{5}$ The inter-rater agreements were computed with ReCal OIR (Reliability Calculator for Ordinal, Interval, and Ratio data) (Freelon, 2013).
} 
As recommended in the MIPVU, a third inter-rater agreement was performed after discussion of cases of disagreement and a last coding session. In this third and final step, the inter-rater agreement after discussion reached a Cohen's kappa of 0.958, which shows "almost perfect agreement" (McHugh, 2012, p. 279). The inter-rater agreement scores are summarized in Table 3:

Table 3

Inter-rater agreement after discussion

\begin{tabular}{lcccccc} 
& $\begin{array}{c}\text { Percent } \\
\text { Agreement }\end{array}$ & $\begin{array}{c}\text { Cohen's } \\
\text { Kappa }\end{array}$ & $\begin{array}{c}\text { Number of } \\
\text { Agreements }\end{array}$ & $\begin{array}{c}\text { Number of } \\
\text { Disagreements }\end{array}$ & $\begin{array}{c}\text { Number } \\
\text { of cases }\end{array}$ & $\begin{array}{c}\text { Number of } \\
\text { decisions }\end{array}$ \\
\hline $\begin{array}{l}\text { Inter-rater } \\
\text { agreement } \\
\text { after } \\
\text { discussion }\end{array}$ & $98.8 \%$ & 0.958 & 484 & 6 & 490 & 980 \\
\hline
\end{tabular}

The researchers selected 21 MRWs out of $\sim 60$ (depending on the rater: the first researcher had identified 69 MRWs, while the second researcher had identified 63 MRWs) based on the fact they all had been initially identified as MRWs in the first coding by both researchers and that they were evenly distributed in the text.

During the second phase of the experiment, 47 Master's students in translation were asked to translate the same text used for the coding by the two researchers during a sight translation class. The aim was to let students get acquainted with the text. The following week, the same students received a two-hour seminar aimed at simplifying Lakoff \& Johnson's (1980) conceptual metaphor theory and at giving explanations of the MIPVU coding. Students were given a short manual for coding, examples of metaphorical coding, a spreadsheet with the 21 selected items in context and the source text from which the items were extracted and which they had translated the week before.

Then, students were asked to code the 21 selected items following the simplified explanations they were given about the MIPVU. The decision to ask students to code only a third of all MRWs identified by the researchers was motivated by the idea to limit the duration of the coding in order to avoid both making it too tiresome for students and going past a class hour. All collected data is used with the students' permission and all the names are anonymized in the following figures and plots.

Students, who were not aware that the selected items had previously been identified as metaphorical, were asked to decide whether those items were 
metaphorical or non-metaphorical by either applying a code of 1 (= metaphorical item) or 2 (= non-metaphorical item). Items were presented within their context (in segments) in a spreadsheet to facilitate coding and to enable students to comment their decisions if they felt the need to, as depicted in Figure 1:

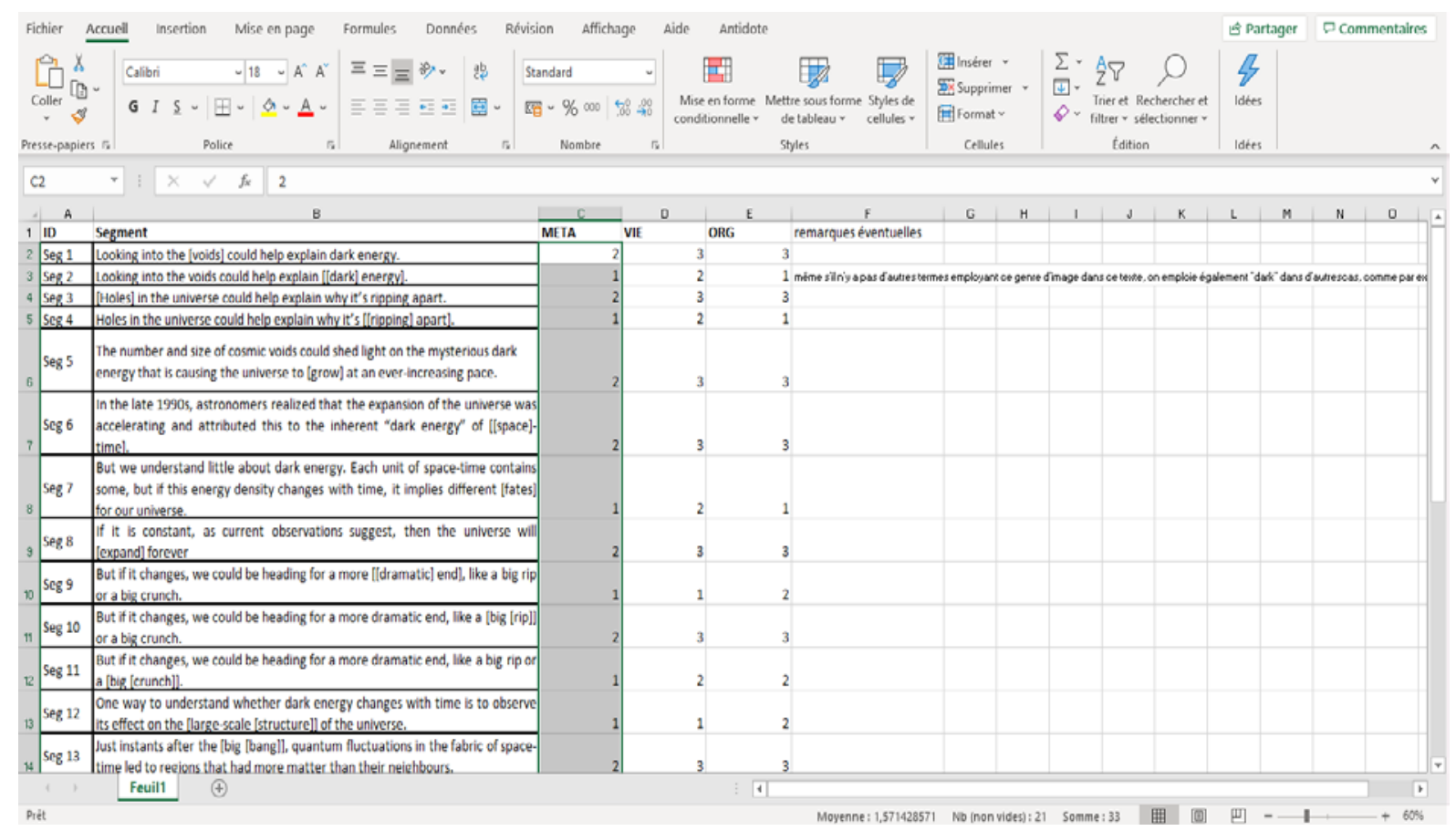

Figure 1: Spreadsheet given to students for the coding experiment

The initial experiment included coding for metaphoricity, conventionality of metaphorical items (inspired and simplified from Kövecses' typology (2010, p. 324) and with the use of a terminology database and a dictionary to verify metaphors' presence in usage and polysemy) and metaphorical entailment (based on students' ability to infer a thematic bond with other metaphorical words or terms). However, metaphorical conventionality ("VIE", for "life" in French, in Figure 1) and entailments ("ORG", for "organization" in French, in Figure 1) are not discussed in this article, as students found it more difficult to understand and code these concepts than conceptual metaphoricity. Therefore, the details given here only concern the coding of metaphoricity of items ("META" in Figure 1). At the end of class, every student submitted their spreadsheet on an online platform. Data for metaphoricity was compiled in a new cross-table.

\section{Results of the coding experiment}

The coding of the 21 items by the 47 students shows that globally, students were able to code items as metaphorical in $50.04 \%$ of the cases, as summarized in Figure 2: 


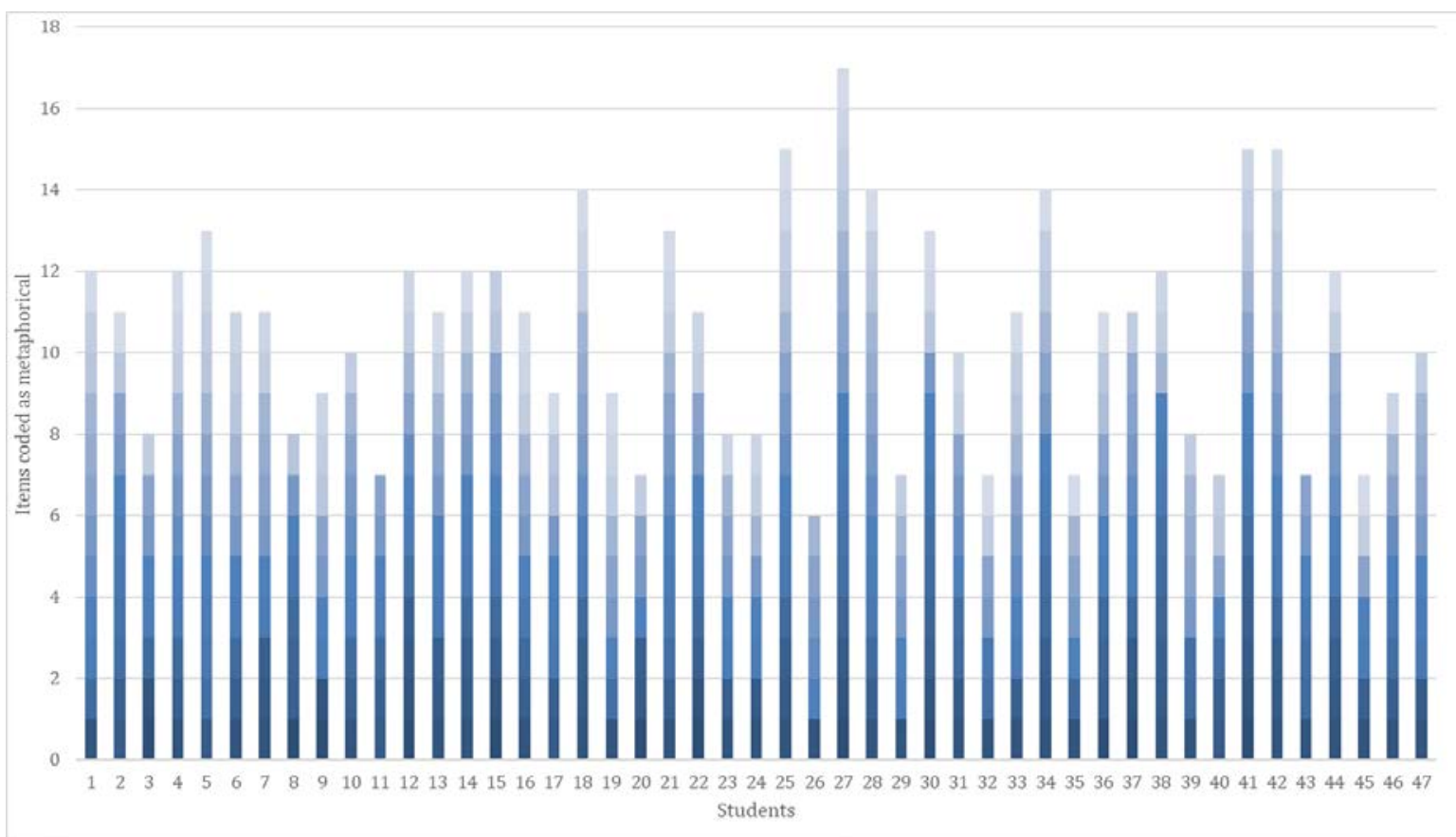

Figure 2: Coding of 21 items by 47 students

The lowest number of metaphorically coded items is 6 out of 21 (by student \#26 in Figure 2 above), while the highest number of metaphorically coded items is 17 out of 21 (by student \#27). The mean of coded items is 11, while the standard deviation of the students' coding is $\sigma=2.70$. As a rule of thumb, the closer the result of the standard deviation is to the mean, the less dispersed is the data:

The standard deviation for one sample is often difficult to interpret on its own; as a guideline, the smaller the SD is in relation to the mean, the less dispersed the data is, that is, the closer individual values are to the mean. (Rasinger, 2013, p.136)

Here, the results show that the coding by students is strongly divergent, which means their abilities to identify metaphors are very different.

Nevertheless, a chi-squared test was run to verify whether the students' coding of metaphorical items and non-metaphorical items was statistically significant and therefore not due to chance ( $\mathrm{Ha}=$ alternative hypothesis) or whether items were indifferently coded as metaphorical or non-metaphorical, meaning that the coding was due to chance alone ( $\mathrm{HO}=$ null hypothesis). The chi-squared test showed that the null hypothesis could be ruled out $\left(p<2.2^{-16}\right)$ and that the coding of items by students was not due to chance alone. Several items were coded fewer times as metaphorical by students, such as "grow", "expand", "evolved", and "regions", while the most frequently coded items were "crunch", "rip", "bang" (as in "big bang"), "fabric", "dark" (as in "dark energy") and "light-years", as shown in Figure 3: 


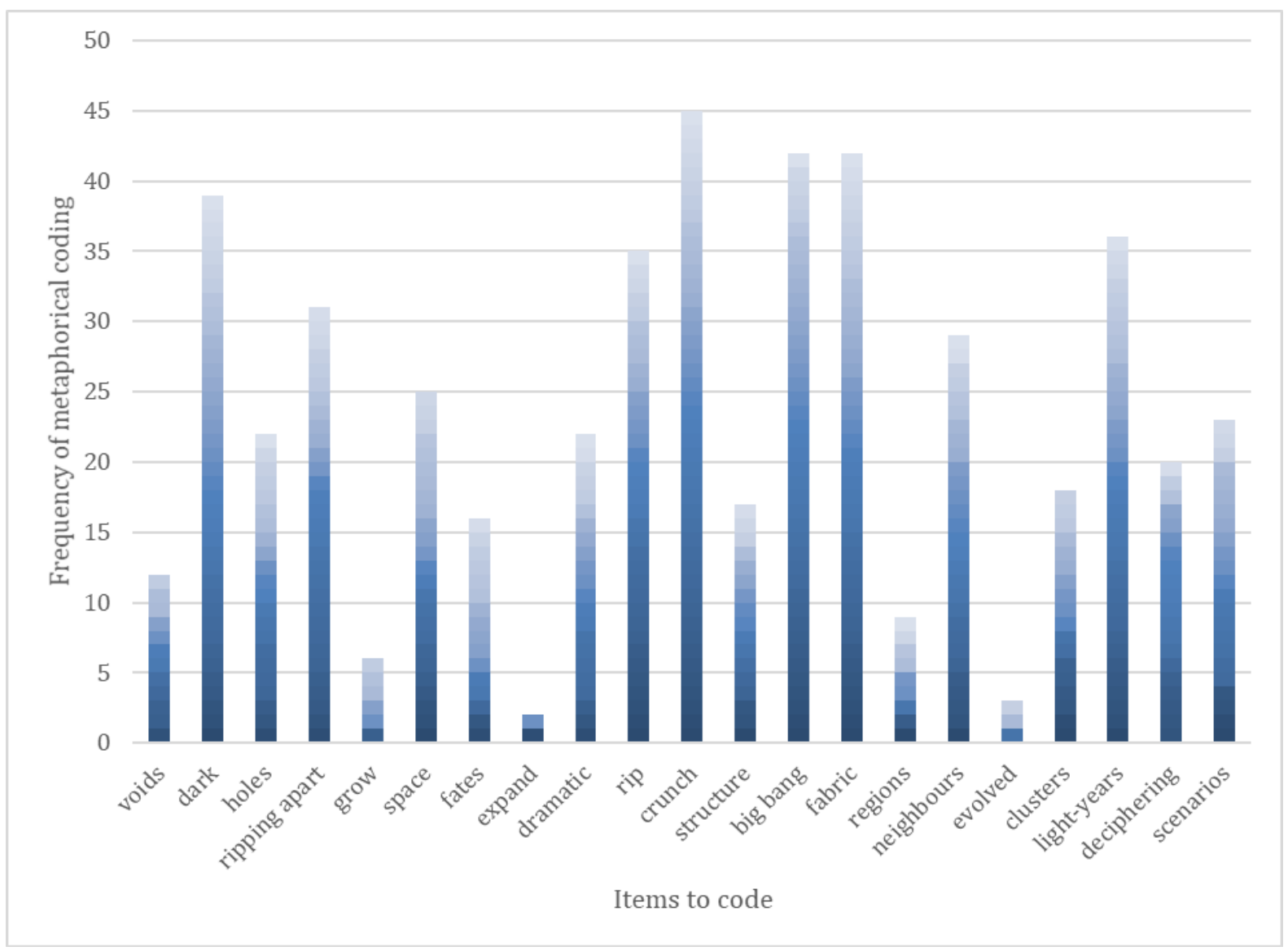

Figure 3: Frequency of items coded as metaphorical

The results of the experiment show that students can identify items as metaphorical in roughly half of the cases after having followed a seminar on the coding of metaphors and that their coding is statistically significant.

\section{Conclusion}

This article stressed the difficulty encountered by translation students in dealing with metaphorical language in vulgarized scientific texts. In a survey led in 2017, twelve students claimed to be able to identify metaphorical language but also admitted having difficulties translating linguistic realizations of metaphors. In addition, an experiment with the aim of correlating the coding of a text for metaphor-related words by two researchers on the one hand and by 47 translation students on the other hand highlighted that students were able to identify MRWs in only $50.04 \%$ of the cases in comparison with the researchers' coding. Nevertheless, a chi-squared test run on the students' coding led to the conclusion that their coding was not arbitrary. A plausible way to improve the skills of translation students in identifying and translating linguistic realizations of metaphors could be through the development of awareness-raising activities. 


\section{References}

Deignan, A. (2008). Corpus Linguistics and Metaphor. In R. W. Gibbs (Ed.), The Cambridge handbook of metaphor and thought (pp. 280-294). New York: Cambridge University Press. https://doi.org/10.1017/CB09780511816802.018

Freelon, D. (2013). ReCal OIR: Ordinal, Interval, and Ratio Intercoder Reliability as a Web Service. International Journal of Internet Science, 8(1), 10-16.

Gibbs, R. W. (Ed.). (2008). The Cambridge handbook of metaphor and thought. New York: Cambridge University Press. https://doi.org/10.1017/CB09780511816802

Jacobson, T. A., \& Parentani, R. (2007). An Echo of Black Holes. Scientific American, 17(1), 12-19. https://doi.org/10.1038/scientificamerican0407-12sp

Kövecses, Z. (2010). Metaphor: A practical introduction (2nd ed). New York: Oxford University Press.

Lakoff, G. (1993). The contemporary theory of metaphor. In A. Ortony (Series Ed.), Metaphor and thought (2nd ed., pp. 203-251). Cambridge: Cambridge University Press. https://doi.org/10.1017/CB09781139173865.013

Lakoff, G., \& Johnson, M. (1980). Conceptual Metaphor in Everyday Language. The Journal of Philosophy, 77(8), 453-486. https://doi.org/10.2307/2025464

Levshina, N. (2015). How to do linguistics with R: Data exploration and statistical analysis. Amsterdam; Philadelphia: John Benjamins.

https://doi.org/10.1075/z.195

McHugh, M. L. (2012). Interrater reliability: The kappa statistic. Biochemia Medica, 22(3), 276-282. https://doi.org/10.11613/BM.2012.031

Rasinger, S. M. (2013). Quantitative research in linguistics: An introduction (Second Edition). London; New York: Bloomsbury.

Scharf, C. (2012). The Benevolence of Black Holes. Scientific American, 307(2), 34-39. https://doi.org/10.1038/scientificamerican0812-34

Schmitz, C. (2003). Lime Survey: An Open Source survey tool. Hamburg, Germany: Limesurvey GmbH.

Steen, G. (2007). Finding Metaphor in Grammar and Usage: A Methodological Analysis of Theory and Research. Amsterdam: John Benjamins. https://doi.org/10.1075/celcr.10

Steen, G., Dorst, A. G., Herrmann, J. B., Kaal, A., Krennmayr, T., \& Trijntje, P. (2010). $A$ method for linguistic metaphor identification: From MIP to MIPVU. Amsterdam; Philadelphia: John Benjamins. https://doi.org/10.1075/celcr.14 